\title{
Liability-driven Performance Attribution
}

\author{
by Auke Plantinga and Robert van der Meer'
}

\begin{abstract}
The subject of this paper is the performance measurement of the investment process of liability-driven investors, e.g. insurance companies and pension funds. It starts with a historical overview of the development of performance measurement in an "asset only" approacl. However, when an investor introduces Asset-Liability Management, performance measurement based on an "asset only" approach can be misleading. Necessary conditions and solutions for a performance measurement system in a liability context will be discussed.
\end{abstract}

\section{Introduction}

Almost every investor has to meet specific liabilities. The nature of these liabilities plays an important role in the formulation of an investment strategy. Investors who use their liability structure as a determinant of investment strategy will be addressed as liability-driven investors. ${ }^{2} \mathrm{~A}$ rational strategy for a liability-driven investor is to minimize the risk of not being able to meet these liabilities. This will also minimize the risk that the investor will use own funds (surplus) in order to meet the liabilities.

Although some attention has been paid to the performance measurement of liabilitydriven investors like insurance companies and pension funds, the link between the nature of their liabilities and performance measurement did not attract direct attention. Until very recently, literature on performance measurement focused on the performance of assets only, ignoring the relationship with the liability structures. However, some authors ${ }^{3}$ do recognize the problems that arise when performance of a liability-driven investor has to be measured.

This paper starts with a short summary addressing the historical developmemt of performance measurement, followed by some methods of attributing performance. Next, a

\footnotetext{
${ }^{1}$ Robert A.H. van der Meer is a part-time professor of Investments at the University of Groningen and is a member of the Executive Board of Aegon N.V. Auke Plantinga is assistant professor of finance and investments at the University of Groningen.

${ }^{2}$ For a comprehensive overview of strategies for institutions practicing Asset Liability Management, see Van der Meer and Smink (1993).

${ }^{3}$ See for example Fong, Pearson and Vasicek (1983), Leibowitz, Kogelman and Nader (1992), and Greer (1992).
} 
short introduction to Asset-Liability Management (ALM), and the consequences for a performance measurement framework will be described. Then, a liability-driven performance attribution will be derived for different types of liability structures. The article ends with a short discussion on the practical use of the proposed models.

\section{2. “Asset-only" performance measurement}

Performance measurement of investment portfolios is deeply rooted in what is known as "Modern Portfolio Theory" (MPT). Although MPT suggests the existence of one single theoretical framework, it in fact refers to a whole family of theories like the capital Asset Pricing Model (CAPM) and the Arbitrage Pricing Theory (APT). These theories are formulated as ex ante equilibrium models. Practitioners as well as academics make extensive use of those theories to develop applications for ex post evaluation of investment processes. However, most of the applications fail to recognize the importance of the liability structure, and therefore we will address these methods as "asset-only" performance measurement.

Performance measurement is aimed at measuring whether or not the actual performance of the investments meets the specified goal, and how decisions made in the investment process contribute to actual performance. The process of performance measurement consists of the following procedures:

- The creation of a benchmark portfolio which is used for assessing realized performance, and which reflects the investment goal;

- The measurement of the realized return of both the actual and the benchmark portfolio;

- The attribution of the differences between the returns of the actual and the benchmark portfolio into components that refer to decisions made in the investment process.

The benchmark portfolio which captures the return and risk characteristics of the available investment opportunities subject to the risk preferences of the investor, serves as the investment goal. One approach in constructing this benchmark portfolio is the use of the Capital Asset Pricing Model. This model suggests the use of the Capital Market Line as a benchmark that is able to reflect both the market conditions and the investor's risk preferences.

An important assumption made in both the CAPM and the ATP concerns the existence of efficient markets and homogeneous expectations. Market participants do possess all the available information, which will prevent any of the participants from obtaining systematically excessive returns. Portfolio managers believing in efficient markets will employ one of the theoretical models and try to implement a passive strategy by replicating the benchmark portfolio. A performance measurement system for such a so-called passive investor should reflect his success and efficiency in doing so. However, many portfolio managers claim the possession of superior information and/or superior forecasting abilities. These so-called active investors try to select specific assets or asset categories they expect to perform extraordinarily well. The former activity is often referred to as selectivity, and the latter as timing. A framework for performance measurement should therefore be able to measure the return of both activities.

Currently, the Capital Asset Pricing Model, as developed by Sharpe (1964), Lintner (1965) and Mossin (1966) is a main supplier of theoretically justified benchmarks and performance measures. The Capital Market Line (CML) can serve as a benchmark for broadly diversified portfolios, and the Security Market Line (SML) for less diversified portfolios 
or parts of the total portfolio. Based on both the CML and the SML, several risk-adjusted performance measures have been developed. Jensen (1969), Treynor (1965) and Sharpe (1966) were in the late 60's the first to apply CAPM in risk adjusted performance measurement.

From the seventies until the present, these measures have been widely employed in empirical research of the performance of institutional investors. Some spin-offs of these empirical studies were further refinements suggested to adapt the Jensen, Treynor and Sharpe measures to a more sophisticated level. ${ }^{4}$

\section{Attribution}

Performance attribution is aimed at attributing the realized excess return of an investment portfolio to decisions of investment management. As different strategies entail different decisions, the choice of the investment strategy is of importance in determining an attribution framework. We will distinguish between strategies based upon vision with respect to future market developments and strategies using no specific vision with respect to future market developments.

Strategies based upon vision

A manager implementing a strategy based upon vision with respect to future market developments can outperform the market if he is able to use some forecasting skill, enabling him to:

- Select within an asset class securities which will perform better than may be expected on the basis of a pricing model (selection);

- Predict performance of entire asset classes. As a result the manager will change his asset mix or will adjust the systematic risk of the asset class (timing).

\section{Strategies without vision}

A manager with no specific vision regarding future market developments can, following the conclusion of the CAPM, invest in the market index. The performance of this manager can be measured as the success in replicating the returns generated by the market index. His performance is measured using his tracking error. The sponsor can further enhance evaluation by estimating the likelihood of the manager underperforming the benchmark..$^{5}$

For both stocks and bonds separately, frameworks for performance measurement have been developed. For stocks, a typical example is the framework developed by Fama (1972), which attributes performance, using the CAPM, in components referring to qualities of management and external factors. By changing the beta of his investment portfolio the manager can time the market, while overweighting specific securities results in selection abilities. The return of these qualities are measured against the foregone diversification returns.

For bonds, Fong, Pearson and Vasicek (1983) proposed an accurate decomposition of performance. They distinguish external and internal factors. External factors are determined by the interest rate environment and can be split into two parts, namely, an expected and an unexpected component. The expected interest rate $(E)$ can be calculated by mea-

\footnotetext{
${ }^{4}$ For example, see Moses, Cheyney and Veit (1987).

${ }^{5}$ See for instance Franks (1992).
} 
suring the return of a treasury bond index, assuming that the composing bonds at the end of the period are priced according to the implied forward rates. The unexpected component $(\mathrm{U})$ is then determined by the realized rates at the end of the period. Internal factors can be divided into maturity management $(\mathrm{M})$, spread/quality management $(\mathrm{S})$ and selection of specific securities (B). Maturity management is related to the ability of the manager to anticipate interest rate changes. Spread/quality management and selection skill relate to anticipation of abnormal performance of specific sectors and individual securities.

Most investment portfolios of institutional investors consist of several asset classes. Investment management of a multi class portfolio aims at both the composition of the asset mix and the policy within an asset class. However, the security pricing models discussed so far are mainly suitable for the latter. In order to measure the performance of asset mix management, practicians have developed an attribution model which does not rely on a specific pricing model. ${ }^{6}$ This attribution model is suitable for measuring the effects of several types of management decisions, e.g. the management of currency positions. Following the terminology of Cariño, it requires the construction of the following portfolios:

(1) The policy portfolio: this portfolio is constructed using strategic asset allocation or plan weights. Each asset class is assumed to be invested in the market index or benchmark portfolio relevant for the asset class;

(2) The security selected portfolio: this portfolio is invested according to the strategic asset allocation. The return on each asset is determined by actual returns;

(3) The timing allocated portfolio; this portfolio represents the return of the asset allocation of the actual portfolio. Each asset class is assumed to be invested in the benchmark;

(4) The actual realized return on the portfolio.

Portfolio weights and returns are defined in the following way:

$w_{1}$ the weight of asset class $i$ in the portfolio according to the strategic asset allocation;

$w_{i}^{a}$ the actual weight of asset class $i$ in the portfolio;

$\mathrm{R}_{\mathrm{i}}^{\mathrm{a}}$ the realized return on the index of benchmark portfolio;

$r_{i}^{a}$ the realized return on asset class.

The return on each of the portfolios is defined as:

(1) $\sum(w p r p)$

(2) $\sum\left(w p r_{i}^{a}\right)$

(3) $\sum\left(w_{i}^{a} r_{i}^{p}\right)$

(4) $\sum\left(w_{i}^{a} r_{i}^{a}\right)$

Source of performance Calculation

\begin{tabular}{lll}
\hline allocation & $(3)-(1)$ & $\Sigma\left(w_{i}^{a}-w_{p}^{p}\right) r_{i}^{p}$ \\
selection & $(2)-(1)$ & $\Sigma\left(r_{i}^{a}-r_{p}^{p}\right) w_{p}^{p}$ \\
interaction & $(1)-(2)-(3)+(4)$ & $\Sigma\left[w_{i}^{p}\left(r_{i}^{p}-r_{i}^{a}\right)+w_{i}^{a}\left(r_{i}^{a}-r_{i}^{p}\right)\right]$ \\
\hline
\end{tabular}

Deviating the actual asset allocation from the strategic asset allocation causes the allocation or timing effect, while the selection effect is the result of active management within

${ }^{6}$ See Brinson and Fachler (1985) or Cariño (1992). 
the asset classes. The interaction of allocation and selection decisions is described as the interaction effect. ${ }^{7}$

\section{Asset-Liability Management}

The purpose of Asset-Liability Management is to control simultaneously the risk and return of the investments and liabilities of a financial institution. Different risk characteristics of assets and liabilities, which are often addressed as mismatches, can result in significant risk exposures for the return of the surplus of a financial institution. Management of these mismatches is, if exercised properly, crucial in creating value for the owners of the institution. As interest rate risk is one of the most important sources of mismatches, most literature on Asset-Liability Management focusses on interest rate risk.

Babbel and Staking (1989) have derived an analytic relationship between surplus risk, and the difference between asset risk and liability risk:

$$
D_{s}=D_{l}+\left(\frac{A}{S}\right)\left(D_{a}-D_{l}\right)
$$

A : Market value of assets;

$\mathrm{D}_{\mathrm{a}}$ : Duration of assets;

L: Market value of liabilities;

$\mathrm{D}_{\mathrm{I}}$ : Duration of liabilities ;

S: Market value of surplus;

$\mathrm{D}_{\mathrm{s}}$ : Duration of surplus.

The equation shows that the effect of a mismatching $\left(D_{a}-D_{1}\right)$ on surplus is multiplied by the degree of leverage (A/S). For highly levered financial institutions like banks or insurance companies, a small mismatch can result in a significant surplus risk. Therefore, capital structure is of importance in asset liability management.

The possible value effects of optimal capital structure is the subject of a large number of studies. Modigliani and Miller (1958) have demonstrated that in a world with perfect markets the capital structure does not affect the value of the firm. However, as soon as market imperfections are introduced, value effects occur. With corporate taxes only, full debt financing creates a tax shield and maximizes the value of the firm. Furthermore, literature suggests that the existence of an optimal mix of debt and equity can also be explained by a trade-off between the tax shield and costs like for example bankruptcy costs of financial distress or the agency costs of debt (Jensen and Meckling, 1976).

According to Babbel and Staking (1989), the value effects resulting from a duration mismatch are related to the capital structure which is measured by the degree of leverage and the duration differential of assets and liabilities. Their research, based on a sample of 25 property liability insurance companies, reveals value effects which can be attributed to the degree of leverage and the duration of surplus. Their study suggests an optimal leverage of approximately 3.75 , and an optimal surplus duration of about zero for normal levels of leverage.

As a result of an interest rate exposure, both profits and losses can result from interest rate movements. If management is able to control the mismatch, then it is possible to profit effects.

${ }^{7}$ It is quite easy to extend this framework for international portfolios in order to include currency 
from superior interest rate forecasts. If interest rates are expected to fall, the mismatch will be enlarged. In the opposite case the mismatch will be reduced, or - if possible - even reversed. Management possessing superior interest rate forecasting capabilities therefore should deliver positive returns from mismatches.

The interest rate exposure of surplus can be changed by either the duration of the assets or the duration of the liabilities. As this paper is focussed on the investment performance of a liability-driven investor, we will consider only the former. Management of the duration of the investment portfolio can aim at the amount of interest rate sensitive investments (asset allocation) or the interest sensitivity of the investments (duration management).

\section{Performance of a liability-driven investment process}

In addition to the "asset-only" performance measurement, the existence of a liability structure adds two possible value effects. Both effects are a result of the decision to create interest rate risk exposure. The first effect, the timing effect, is the change in the value in the surplus caused by a change in interest rates. The second effect is caused by the magnifying effect of financial leverage on the interest rate sensitivity of surplus.

An appropriate benchmark for measuring the performance of a liability-driven investment portfolio will have to meet the following set of criteria:

1. The benchmark should duplicate the risk and return characteristics of the investment goal ;

2. The benchmark will have to present a real investment alternative;

3. The securities which constitute the benchmark should be valued at market prices.

To construct a benchmark satisfying these criteria, it is necessary to establish a benchmark portfolio which is cash matched with the liability cash outflows. Due to its nature, a cash matched portfolio satisfies criterion 1 . If it is possible to pursue the specified benchmark as a feasible investment strategy, ${ }^{8}$ criterion 2 is met. As soon as public available market prices are available, and certain assumptions regarding market perfections and market efficiency are met, criterion 3 can be satisfied.

In paragraph 5.1 we will develop an attribution framework for a liability structure which can be characterized by interest rate risk only. In paragraph 5.2 we will develop an attribution framework for a liability structure which cannot be characterized by interest rate risk only.

\subsection{Measuring performance using a simple liability structure}

Having identified the necessity to measure investment performance in comparison with the liability structure, we need a model which is able to use a liability-driven benchmark in combination with an attribution model similar to the Brinson \& Fachler framework. Focussing on intercst rate risk in particular, we will derive such a model using a simplified model of a financial institution.

Assumc we have a set of liabilities which can be described as a set of fixed future cash outflows. In order to meet the future liabilities, we invest the amount necessary to replicate

\footnotetext{
${ }^{8}$ See Van der Meer and Smink (1993) for an overview of possible problems with Cash Flow Matching techniques.
} 
the cashflows with a portfolio of fixed income securities. The institutions operate with a surplus large enough to meet the necessary solvency requirements. ${ }^{9}$ The surplus is invested in a separate portfolio, the so called non-liability-driven investments portfolio. This results in the following balance sheet of the financial institution :

Balance sheet

Non-liability-driven investments Liability-driven Investments

\begin{tabular}{l|l}
\hline O & Surplus \\
B & Liabilities
\end{tabular}

L: As the liabilities are assumed to consist of a set of future fixed cash flows, the market value $\mathrm{L}$ is calculated as the value of a bond portfolio with the same cash flows as the liability portfolio.

S: Market value of surplus, defined as Assets $(\mathrm{O}+\mathrm{B})$ minus liabilities;

B : Market value of liability-driven investments;

O: Market value of the non-liability-driven investment portfolio.

Ignoring income from the sale of new policies, the return generated by the portfolio of the financial institution can now easily be calculated: 10

$$
r_{s}^{a} S=r_{o}^{a} O+r_{b}^{a} B-r_{l}^{a} L
$$

$\mathrm{r}_{1}^{\mathrm{a}}$ : Realized return on liabilities, where the liabilities are priced according to the term structure.

$\mathrm{r}_{\mathrm{s}}^{\mathrm{a}}$ : Realized return on surplus;

$r_{b}^{a}$ : Realized return on liability-driven investments (bond portfolio);

$\mathrm{r}_{\mathrm{o}}^{\mathrm{a}}$ : Realized return on non-liability-driven investments.

As interest rate risk is the only source of risk, the termstructure represents the benchmark for both the bond portfolio and the liability portfolio. This results in the following decomposition of performance $:^{11}$

$$
\begin{gathered}
r_{s}^{a}=r_{o}^{a}+\lambda\left(r_{b}^{a}-r_{b}^{p}\right)+\lambda\left(r_{b}^{p}-r_{l}^{a}\right)+\tau\left(r_{b}^{a}-r_{o}^{a}\right) \\
I
\end{gathered}
$$

$\mathrm{rp}$ : the return on bonds, where the bonds are priced according to the term structure;

$\lambda: \quad L / S$, which is also familiar as the financial leverage ratio;

$\tau: \quad(\mathrm{B}-\mathrm{L}) / \mathrm{S}=-(\mathrm{O}-\mathrm{S}) / \mathrm{S}$, which in this paper will be addressed as the funding mismatch ratio.

The attribution framework proposed in formula (3) distinguishes four components of investment performance :

I Realized return on the non-liability-driven portfolio. This return can be analyzed using asset-only performance methodology;

${ }_{9}^{9}$ As a result, in this analysis we will ignore the risk of default. For practical purposes, one can assume that the solvency requirement is calculated according to the appropriate supervisory regulation.

10 The investment of the proceeds from new policies should not be ignored. Although adaption of the equations is rather simple, for reasons of convenience we disregard from the expansion of the balance sheet due to the sale of new policies.

${ }^{11}$ A formal derivation of the liability-driven performance attribution can be found in the appendix. 
II Realized return on the liability-driven portfolio due to active management with respect to all factors, for example credit quality management, sector management, etc., except maturity management;

III The "maturity mismatch" effect: the realized return on the liability-driven portfolio due to active management with respect to maturity management. This component reflects the return from deviating the maturity composition of the investment portfolio from the maturity composition of the liability structure;

IV The "funding mismatch" effect: the performance resulting from managing the amount of funds allocated to the liability-driven investment portfolio (funding mismatch). The funding mismatch ratio can be the result of a strategic decision to divide the investments over the liability-driven and the non-liability-driven portfolio.

In this framework, all components but $\mathbf{I}$ are affected by the liability structure. For an investor using a single asset class to cover his liabilities, components II and III can be analyzed using Fong, Pearson and Vasicek (1983).

The proposed attribution presents some attractive properties for evaluating investment performance :

- Return of the investment portfolio is compared with a benchmark which reflects the risk characteristics of the investment objective: deviations from the risk level of the investment portfolio and the benchmark are used for attributing return differences between investment and benchmark portfolio.

- Using return on surplus as the performance parameter implements directly the overall objective of "shareholder value" in the management accounting system;

- The costs or benefits of allocating more or less funds compared to the market value of liabilities are made distinct.

\section{An example}

The following example of an imaginary insurance company or pension fund illustrates the possibilities of the liability-driven attribution. Assume the following balance sheet with the beginning values of a life insurance office (the values between brackets refer to the year ending market values):

Balance Sheet

\begin{tabular}{ll|ll}
\hline $\begin{array}{l}\text { Non-liability-driven investment } \\
\text { portfolio }\end{array}$ & $100(111.0)$ & Surplus & $110(126.0)$ \\
$\begin{array}{c}\text { Liability-driven investment } \\
\text { portfolio }\end{array}$ & Liabilities & $890(970.0)$ \\
& $900(985.5)$ & &
\end{tabular}

The market value of the liabilities at both the beginning and the end of the year are calculated as the net present value of the liability cash flows using term structure discount rate. The value of the benchmark bond portfolio is also calculated as the net present value of the bond portfolio cash flows using also termstructure discount rates. For reasons of convenience, assume that the liability-driven investment portfolio is invested in treasury bonds only, whereas the non-liability-driven investment portfolio is invested in stocks. ${ }^{12}$ In the following table the realized actual and benchmark returns, which are calculated as ending minus beginning value divided by beginning value, are presented:

12 In order to simplify the analysis, assume that the interest rate sensitivity of stocks is equal to zero. 


\begin{tabular}{|lll|}
\hline asset class & $\begin{array}{l}\text { realized } \\
\text { return }\end{array}$ & $\begin{array}{l}\text { benchmark } \\
\text { return }\end{array}$ \\
Stock & $\mathrm{r}_{\mathrm{o}}^{\mathrm{a}}=11.0 \%$ & $\mathrm{Rg}=12.0 \%$ \\
Bonds & $\mathrm{r}_{\mathrm{b}}^{\mathrm{a}}=9.5 \%$ & $\mathrm{Rp}=10.0 \%$ \\
Liabilities & & $\mathrm{R}_{l}^{\mathrm{a}}=9.0 \%$ \\
\hline
\end{tabular}

The return on the benchmark stock portfolio is the return on an ordinary stock market portfolio like the S\&P 500. Using equation (3) the attribution results in the ncxt table.

\begin{tabular}{|lr|}
\hline I component & return \\
II active (bond) management & $11.00 \%$ \\
III maturity inismatch & $-4.05 \%$ \\
IV funding mismatch & $8.18 \%$ \\
$\quad$ total return & $-0.14 \%$ \\
\hline
\end{tabular}

In this example the major source of return of surplus is the non-liability-driven portfolio $(11 \%)$. Spread and/or quality management costs $4.05 \%(8.18 *(9.50 \%-10.00 \%))$. As predicted by equation (1) the influence of a small mismatch $(10.00 \%-9 \%)$ will be magnified by a high leverage ratio (8.18) and results in this example in an additioal return of $8.18 \%$. With a funding mismatch ratio of $0.0909(10 / 110)$, the influence of the funding mismatch is quite small $(-0.14 \%)$. As a result, return of the liabilities and the corresponding investments delivers an additional return on surplus of $4.0 \%(15.0 \%-11.10 \%)$.

\subsection{Measuring performance using a complex liability structure}

In the previous paragraph a rather simple liability structure was discussed. In reality, more complex liability structures exist. For example, the liabilities of many pension funds are related to the career development of the beneficiaries, or the development of inflation. However, liabilities thus defined often lack matching investments. Managers of pension funds then employ a wide variety of techniques aimed at estimating the required asset allocation most likely to meet the liabilities. This asset allocation, often called the strategic asset allocation, can be seen as the liability structure of the investment department. In fact, this is implicitly assumed in applications of the Brinson \& Fachler attribution framework as described in section 3 .

In this paragraph, the attribution framework proposed in equation (3) will be adapted in order to capture this type of liability structure. In equation (3) the termstructure serves as the benchmark for the liability-driven investments. In equation (4) the strategic asset allocation mentioned before will take this role. Therefore $r_{b}$ will be replaced by the strategic asset allocation, which results in :

$$
r_{s}^{a}=r_{o}^{a}+\lambda\left[\sum_{i} w_{i}^{a} r_{i}^{a}+\sum_{i} w_{i}^{p} r_{i}^{p}\right]-\lambda\left[\sum_{i} w_{i}^{p} r_{i}^{p}-r_{i}^{a}\right]+\tau\left[\sum_{i} w_{i}^{a} r_{i}^{a}-r_{o}^{a}\right]
$$

$w_{i}^{a}=$ the actual portfolio weight for asset class i of the liability-driven investment portfolio;

$w_{i}^{p}=$ the strategic asset allocation for asset class $\mathrm{i}$;

$r_{i}^{p}=$ realized return on benchmark for asset class $\mathrm{i}$; 
$r_{o}^{p}=$ realized return on benchmark for non-liability-driven investments;

$\lambda=\mathrm{L} / \mathrm{S}$, the degree of leverage;

$\tau=(B-L) / S$, the funding mismatch ratio.

This results in the four main components of investment performance :

I The return on non-liability-driven investments;

II The return on active investment management of the liability-driven investments: this component can be further analyzed using the Brinson \& Fachler attribution;

III The return on the strategic asset allocation, or, in other words, how accurate was the strategic asset allocation as an approximation for the liability structure;

IV The return on the funding mismatch, which is defined as similar to the simple framework of paragraph 5.2.

Compared with the simple liability structure in paragraph 5.1, where the target asset allocation for the liability-driven investment portfolio was a $100 \%$ investment in bonds, this multiple asset target allocation creates allocation opportunities by deviating the tactical asset allocation from the strategic asset allocation. As component II of equation (5) corresponds with the difference between the actual portfolio and the policy portfolio of the Brinson and Fachler attribution, the latter can be used to analyze component II even further. This will be illustrated in the example at the end of this paragraph.

\section{An example}

Assume that the following balance sheet represents assets and liabilities of a pension fund. Using for example scenario analysis, the pension fund has established a strategic asset allocation which is likely to meet the liabilities. The portfolio invested in the representative benchmarks according to the strategic asset allocation is assumed to represent the value of the liabilities.

\begin{tabular}{cc|lrr}
\multicolumn{6}{c}{ Balance Sheet 13} \\
\hline Non-Liability-driven Investments & $200(240)$ & Surplus & $225(310)$ \\
Liability-driven Investments & $1050(1170)$ & Liabilities & $1000(1100)$ \\
Bonds & $600(684)$ & & & \\
Stocks & $450(486)$ & & &
\end{tabular}

The reader can verify from these figures that the actual returns for the composing elements of the balance sheet are:

Actual returns on balance sheet components

\begin{tabular}{ll|ll}
\hline Non-Liability-driven Investments & $20.0 \%$ & Surplus & $24.0 \%$ \\
Liability-driven Investments & $11.4 \%$ & Liabilities & $10.0 \%$
\end{tabular}

Suppose that the strategic asset allocation implies an allocation of $50 \%$ of the funds to bonds and $50 \%$ of the funds to stock. The following table presents asset class weights and returns of both the actual and the benchmark portfolio:

${ }^{13}$ Like the example in paragraph 5.1, values between brackets refer to ending values. For reasons of convenience, we ignore intermediate cashflows and use beginning portfolio weights for the benchmark portfolio. 


\begin{tabular}{|l|cc|cc|}
\hline \multirow{3}{*}{ Bonds } & \multicolumn{2}{|c|}{$\begin{array}{c}\text { Actual Portfolio } \\
\text { weights }\end{array}$} & returns & \multicolumn{2}{c|}{$\begin{array}{c}\text { Benchmark Portfolio } \\
\text { weights }\end{array}$} & return \\
\cline { 2 - 5 } Stocks & $57.1 \%$ & $14.0 \%$ & $50 \%$ & $11.0 \%$ \\
Total & $42.9 \%$ & $8.0 \%$ & $50 \%$ & $10.0 \%$ \\
\hline
\end{tabular}

In this example, the funding mismatch ratio $\tau$ is $0.20,(1050-1000) / 250$, while the leverage ratio $\lambda$ is 4 , (1000/250). Applying equation (4) delivers the following performance decomposition :

\begin{tabular}{|lr|ll|}
\hline \multicolumn{2}{|c|}{ component } & return & $\begin{array}{l}\text { Decomposition of component II } \\
\text { according to Brinson and Fachler }\end{array}$ \\
\hline I & non-liability-driven investm.20.0\% & & $0,50 \%$ \\
II liability-driven investments & $3.7 \%$ & $\begin{array}{l}\text { selection } \\
\text { allocation } \\
\text { interaction }\end{array}$ & $0.07 \%$ \\
& & total component II & $0.35 \%$ \\
\cline { 3 - 4 } & & & \\
\hline III strategic asset allocation & $2.0 \%$ & & \\
IV funding mismatch & $-1.7 \%$ & & \\
total return & $24.0 \%$ & & \\
\hline
\end{tabular}

\section{Discussion}

After having identified the necessity of liability-driven performance measurement, we have derived two models suitable for identifying returns in a liability-driven investment environment. The first model is based on a rather simple liability structure which could be easily replicated using cash matching techniques. The second model is based on a more complex liability structure. Both models are basically the same, the first model using a single asset class to match liabilities and the second model using multiple asset classes to match liabilities. In addition to the Brinson and Fachler model, the returns are adapted to the amount of leverage in order to reflect returns on surplus. Furthermore, a useful distinction is made between liability-driven and non-liability-driven investments. The corresponding factor $\tau$ reflects the return of allocating funds over liability and non-liability-driven investments. For example, applied to a cash flow matching technique, this factor shows the return resulting from the fact that initially the market value of the investments exceeded the market value of the liabilities.

Both models can be combined with several advanced performance measurement methodologies. The Fong, Pearson and Vasicek methodology is very useful for the fixed income investments, as it identifies timing returns in a rather precise way. Alternatively, Greer (1992) proposed a method combining stratified sampling techniques with cash matching techniques in order to construct a liability-driven benchmark. His approach shows that a benchmark constructed in this way can be used to evaluate the performanc of both an immunization strategy and active strategies with respect to quality sector. It is therefore a suitable method for splitting up the active bond management part (III) in equation (3). 


\section{Conclusion}

Founded in Modern Portfolio Theory, asset based performance measurement is the subject of a huge amount of research during the past twenty-five years. Quite sophisticated frameworks have been developed to measure timing and selection abilities of mutual funds as well as investment managers.

However, liabilities are main determinants of investment policy and therefore the structure of the liabilities is of importance for the choice of an appropriate investment strategy. Asset-Liability Management aims at simultaneously managing both investments and liabilities. As small mismatches combined with significant leverage can result in large surplus returns, ALM is likely to pay off. Therefore, performance measurement as a tool for evaluating the investment process should supply information with respect to the returns of mismatches in conjunction with leverage. As a result, performance measurement systems will have to be adjusted. We have discussed four possible benchmarks and we have developed two performance attribution frameworks. The proposed framework offers great flexibility for extension towards other elements of investment management, and resembles already used techniques in the investment community.

\section{REFERENCES}

BABBEL, David F. and STAKING, Kim B., "The Market Reward for Insurers that Practice Asset Liability/Management", Goldman Sachs, 1989.

BRINSON, G. P. and FACHLER, N., "Measuring non-U.S. equity portfolio performance", Journal of Portfolio Management, Spring 1986, pp. 73-76.

CARIÑO, David, 1992, "Performance calculations", Frank Russell, Technical Note. 6.

FAMA, E. F., "Components of Investment Performance", Journal of Finance, June 1972, pp. 551-567.

FRANKS, Edward C., "Targeting Excess-of-Benchmark Returns", Journal of Portfolio Management, Summer 1992, pp. 6-12.

FONG, Gifford, PEARSON,Charles and VASICEK, Oldrich, "Bond Performance: Analyzing sources of return", Journal of Portfolio Management, Spring 1983.

GREER, Boyce I., "Market Oriented Benchmarks for Immunized Portfolios", Journal of Portfolio Management, Spring 1992.

JENSEN, M., "Risk, the Pricing of Capital Assets, and the Evaluation of Investment Portfolios", Journal of Business, April 1969, pp. 167-247.

JENSEN, M. and MECKLING, W., "Theory of the firm: Managerial Behavior, Agency Costs and Ownership Structure, Journal of Financial Economics, October 1976, pp. 305-360.

LEIBOWITZ, Martin L., KOGELMAN Stanley and NADER, Lawrence N., "Asset performance and surplus control: A dual-shortfall approach", Journal of Portfolio Management, Winter 1992. 
LINTNER, John, "Security Prices, Risk, and Maximal Gains from Diversification" Journal of Finance, December 1965, pp. 587-615.

MEER, Robert van der, and SMINK, Meije, "Strategies and Techniques for Asset Liability Management: an Overview" The Geneva Papers on Risk and Insurance, No. 67, 1993, pp. 144-157.

MODIGLIANI, F. and MILLER, M. H., "The Cost of Capital, Corporation Finance and the Theory of Investment", American Economic Review, June 1958, pp. 261-297.

MOSES, Edward A., CHEYNEY, John M. and VEIT, E. Theodore, 1987, "A new and more complete performance measure" Journal of Portfolio Management, March, pp. 1595-1611.

MOSSIN, J., "Equilibrium in a Capital Asset Market", Econometrica, October 1966, pp. 768-783.

SHARPE, W., "Capital Asset Prices: A Theory of Market Equilibrium under Conditions of Risk", Journal of Finance, September 1964, pp. 425-442.

SHARPE, W., "Mutual Fund Performance", Journal of Business, January 1966, pp. 119-138.

TREYNOR, J., "How to Rate Management of Investment Funds", Harvard Business Review, January/February 1965, pp. 63-75. 


\section{Appendix : Deriving the LDPA-framework}

LDPA-framework for a simple liability structure

The income of the financial institution can be written as:

$$
r_{s}^{a} S=r_{o}^{a} O+r_{b}^{a} B-r_{l}^{a} L
$$

Dividing both sides by $\mathrm{S}$ delivers:

$$
r_{s}^{a}=r_{o}^{a} \frac{O}{S}+r_{b}^{a} \frac{B}{S}-r_{l}^{a} \frac{L}{S}
$$

Writing the realized income from the bond portfolio as,

$$
r_{b}^{a} B=r_{b}^{a} L+r_{b}^{a}(B-L)
$$

and writing the return on non-liability-driven investments as:

(4)

$$
r_{o}^{a}=r_{o}^{a} S+(O-S) r_{o}^{a}
$$

Now we can rewrite equation 2 as:

$$
r_{s}^{a}=r_{o}^{a} \frac{S}{S}+\frac{O-S}{S} r_{o}^{a}+r_{b}^{a} \frac{L}{S}+\frac{B-L}{S} r_{b}^{a}-r_{l}^{a} \frac{L}{S}
$$

In order to gain some transparency in equation 5 , let the financial leverage, $\mathrm{L} / \mathrm{S}$, be $\lambda$, and let the funding mismatch ratio, (B-L)/S, be $\tau$. This results in the basic form of the liabilitydriven performance attribution:

$$
r_{s}^{a}=r_{o}^{a}-\lambda\left(r_{b}^{a}-r_{l}^{a}\right)-\tau\left(r_{b}^{a}-r_{o}^{a}\right)
$$

To distinguish between components attributable to unexpected events in the liability portfolio and between components attributable to management of the investment portfolio we will use the term structure of interest rates. Repricing all liability cash flows according to the termstructure, the change in value of these repriced liabilities becomes $r_{l}^{a}$. In order to distinguish between the interest rate environment and other sources of return, the investment portfolio can also be repriced according to the termstructure, and results in $r_{b}^{p}$. Now, equation (3) of the main text can be derived:

$$
\begin{gathered}
r_{s}^{a}=r_{o}^{a}+\lambda\left(r_{b}^{a}-r_{b}^{p}\right)+\lambda\left(r_{b}^{p}-r_{l}^{a}\right)+\tau\left(r_{b}^{a}-r_{o}^{a}\right) \\
i i
\end{gathered}
$$

